\title{
TRANSCRIAÇÃO, TRANSCONCEITUAÇÃO E POESIA
}

\author{
Ricardo Gessner* \\ Universidade Estadual de Campinas
}

Resumo: Transcriação é um termo bastante utilizado no campo da tradução; surgiu em um determinado contexto cultural, desenvolvido principalmente a partir do Movimento da Poesia Concreta em vista de uma aplicação específica, condizente às reinvindicações do mesmo. Este trabalho tem como principal objetivo delimitar um matiz conceitual de transcriação, pautado nas teorizações de Haroldo de Campos e aplicá-lo numa análise da tradução do poema "Blanco", de Octavio Paz.

Palavras-chave: Tradução de literatura. Transcriação. Haroldo de Campos. Octavio Paz.

\section{TRANSCREATION, TRANSCONCEPTUALIZATION AND POETRY}

\begin{abstract}
Transcreation is widely used in discussions about translation theory. It was created in a particular cultural context, developed mainly from the Concrete Poetry in view of a specific application befitting to its proposals. This paper aims to define a conceptual hue for trancreation, based on theories of Haroldo de Campos, and apply it to an analysis of the translation of the poem "Blanco", by Octavio Paz.
\end{abstract}

Keywords: Literary translation. Transcreation. Haroldo de Campos. Octavio Paz.

\footnotetext{
* Doutorando em Teoria e História Literária pela Universidade Estadual de Campinas. Mestre em Teoria e História Literária pela Universidade Estadual de Campinas (2013). Professor colaborador na Universidade Estadual do Norte do Paraná - UENP, campus Jacarezinho, atuando na área de Literatura. Jacarézinho, Paraná, Brasil. E-mail: rigessner@yahoo.com.br
} 


\section{Introdução}

No decorrer da década de 1950, os irmãos Augusto e Haroldo de Campos, em conjunto com Décio Pignatari, publicaram vários manifestos apresentando e discutindo as principais propostas do que chamavam de Concretismo, ou Movimento da Poesia Concreta. Mas foi no ano de 1958 em que publicaram o "Plano-piloto para poesia concreta" - o "resultado" de suas pesquisas em matéria de poesia, sintetizando todo o pensamento, proposta e corpo teórico daquele novo movimento.

Em resumo as principais "reivindicações poéticas" giravam em torno da valorização da materialidade linguística, ou seja, de aspectos fônicos (sonoridade), grafia, e, principalmente, da disposição gráfica das palavras (ou parte delas) pelo branco da página. A forma vinha em primeiro plano, sendo que o aspecto semântico seria originado na interação entre poema e leitor; ou seja, o leitor faria recortes ou "opções" de leitura. É o que os concretistas chamavam de "leitura aberta".

Para estruturar teoricamente esse movimento, o grupo trouxe ao contexto brasileiro diversos autores, muitos deles ainda sem tradução para a língua portuguesa. Eram autores como Ezra Pound, Stéphane Mallarmé, Vladmir Maiakovski, e.e. cummings, James Joyce, poetas e romancistas que primaram pela ruptura dos padrões canônicos, constituindo outros modos produção literária. Sendo assim, o grupo concretista começou a elaborar traduções desses autores para a língua portuguesa, de modo que o público mais amplo tivesse acesso a esse corpus.

Porém um desafio se impunha: no processo de tradução, como dar conta da exploração de recursos da materialidade linguística? Se a significação do texto é um aspecto secundário, ou melhor, se a significação ou os efeitos de sentido estão na própria forma do texto, como traduzir esses efeitos para outra língua?

Diante desse desafio elaboraram uma nova prática de tradução: a transcriação, esta desenvolvida a partir de algumas teorizações do poeta norte-americano Ezra Pound. O principal objetivo da 
transcriação é a recriação do texto original na língua de chegada, ou seja, explorar os recursos articulados na língua de partida e reproduzi-los analogamente na língua de chegada. A partir da transcriação vários autores, até então ausentes no âmbito da língua portuguesa, foram traduzidos, apresentados e inseridos no âmbito da discussão cultural. Também é importante lembrar que a transcriação não foi aplicada somente aos autores supracitados, mas Augusto de Campos, Haroldo de Campos e Décio Pignatari também traduziram textos clássicos, como, por exemplo, a Ilíada, de Homero, e excertos da Divina Comédia, de Dante.

Diante disso, o objetivo central deste trabalho é discutir um possível matiz teórico para o termo transcriação, verificando sua aplicabilidade, seus limites, e como pode contribuir para o processo de tradução. O poema "Blanco", de Octavio Paz "transcriado" por Haroldo de Campos, ambos incluídos no volume intitulado Transblanco (1994), organizado pelo Haroldo de Campos, será utilizado como principal referência literária.

\section{Transcriação: uma transconceituação?}

Uma das principais dificuldades ao se trabalhar com transcriação é justamente realizar uma delimitação conceitual. Em primeiro lugar, não se trata de um conceito; o termo foi cunhado por Haroldo de Campos para designar um processo de tradução, que se caracteriza por ser criativo. Diz mais respeito, portanto, a uma prática do que a uma teoria, e por não ter uma delimitação conceitual pré-estabelecida, facilmente torna-se escorregadio, servindo-se aos mais diferentes propósitos. Nesse sentido, este trabalho intenta elaborar, mesmo que brevemente, uma reconstituição do uso do termo a partir das fontes ensaísticas de Haroldo de Campos.

Um texto que pode servir como base para nosso intuito é "Da tradução como criação e como crítica", incorporado no volume Metalinguagem e outras metas (2004). Mesmo que o autor não se proponha a conceituar ou categorizar o termo transcriação - que 
nem sequer é utilizado no ensaio -, é possível identificar um horizonte teórico que poderá contribuir para delimitá-lo.

De maneira geral, é possível estabelecer três grandes campos teóricos que podem ocupar as bases de uma possível "teoria da transcriação", são eles: Teoria da Literatura, Teoria da Informação e Teoria da Tradução. No contexto do ensaio de Haroldo de Campos, para cada campo um autor em específico ocupará um lugar de proeminência: Albercht Fabri, Max Bense e Ezra Pound, respectivamente. É a partir da concepção de cada um desses autores, de suas concepções particulares dentro de seus respectivos campos, que será possível matizar as bases teóricas da transcriação.

Haroldo de Campos inicia o ensaio retomando um texto de Albercht Fabri, "Preliminares a uma Teoria da Literatura". A tese central é a de que

'a essência da arte é a tautologia', pois as obras artísticas 'não significam, mas são'. Na arte, acrescenta, 'é impossível distinguir entre representação e representado'. Detendo-se especificamente sobre a linguagem literária, sustenta que o próprio desta é a 'sentença absoluta', aquela 'que não tem outro conteúdo senão sua estrutura', 'a que não é outra coisa senão o seu próprio instrumento’ (CAMPOS, 2004, p. 31).

Isso pressupõe uma concepção de que o texto literário não possui ou apresenta outra realidade a não ser a sua própria. Isto é, o texto literário é autorreferencial, não aponta para uma realidade exterior. É uma concepção coerente ao projeto concretista, que estabelece o poema - e por extensão, o texto literário - como objeto autônomo: não comunica nada além de sua própria forma. Por conseguinte, essa perspectiva pressupõe outro modo de interpretação, em que a instância semântica é relegada a uma importância menor ou nem mesmo é considerada: o conteúdo é ou se constitui na própria forma, sendo que a "interpretação" passa a ser uma interpretação de formas. 
Nesse sentido, um paralelo coerente e que por vezes será um referencial teórico importante em Haroldo de Campos é o linguista Roman Jakobson, especialmente o texto "Linguística e Poética", presente na coletânea de ensaios Linguística e Comunicação (1971). O principal intuito de Jakobson é englobar o campo da Poética dentro do campo de estudos da Linguística. Para isso, parte do princípio de que o texto literário é uma espécie de comunicação e justifica seu argumento com a elaboração de um esquema comunicacional, representado a seguir:

\section{REFERENTE}

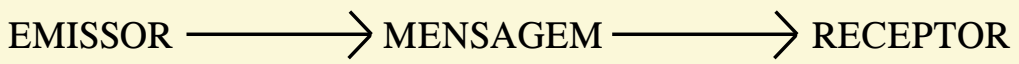

\section{MEIO}

\section{CÓDIGO}

Basicamente, o esquema funciona da seguinte maneira: um "Emissor" envia uma "Mensagem" a um "Receptor"; essa "Mensagem" é transmitida através de um "Meio", está enquadrada em um determinado "Código" comum ao Emissor e ao Receptor, e faz parte de um "Referente", que é o contexto ou o assunto.

Segundo Jakobson, no processo comunicacional é possível enfatizar determinada instância, gerando diferentes disposições hierárquicas entre os fatores e, consequentemente, constituindose diferentes esquemas de comunicação, chamados de "Função comunicacional”. No caso do texto literário, este é caracterizado quando a ênfase recai sobre a "Mensagem", constituindo o que se chama de "Função Poética": articula-se aspectos específicos e constituintes dessa instância, como a materialidade linguística: sonoridade, grafia, etc.

A "mensagem" voltada para si mesma é o equivalente à "tautologia", que caracteriza a "essência da arte", como disse Albercht 
Fabri. “As obras de arte não significam, mas são”, ou seja, nos termos de Jakobson não se estabelece uma relação direta com as demais instâncias do processo comunicativo: o aspecto constituinte é a "Mensagem" voltada para si mesma.

Tradicionalmente associa-se a tradução à instância do significado: procura-se traduzir o que o texto significa. Essa é uma perspectiva que gera problemas se confrontada com a concepção de literatura aqui apresentada. Aquela "sentença absoluta" da qual fala Fabri, "não pode ser traduzida, pois 'a tradução supõe a possibilidade de se separar o sentido e a palavra'" (CAMPOS, 2004, p. 32). Se há uma predominância da forma, como traduzir um texto dessa espécie? Seria necessária, portanto, outra concepção de tradução. Seguindo as reflexões de Fabri, prossegue Haroldo de Campos:

O lugar da tradução seria, assim "a discrepância entre o dito e o dito”. A tradução apontaria, para Fabri, o caráter menos perfeito ou menos absoluto (menos esético, poderse-ia dizer) da sentença, e é nesse sentido que ele afirma que "toda tradução é crítica", pois "nasce da deficiência da sentença", de sua insuficiência para valer por si mesma. "Não se traduz o que é linguagem num texto, mas o que é não-linguagem”. "Tanto a possibilidade como a necessidade da tradução residem no fato de que entre signo e significado impera a alienação”. (CAMPOS, 2004, p. 32).

Isso significa que dentro dessa concepção, por mais que a arte seja tautológica, é impossível atingir um estado absoluto dessa tautologia; algo sempre "escapa". E o processo de tradução atém-se justamente nesse "escape", onde não há linguagem, mas a interpretação é necessária para a tradução. Daí que a tradução, nesse processo, é também crítica.

Outro referencial teórico importante é Max Bense, filósofo e crítico. Mais especificamente, sua distinção de base semiótica e 
teórico-informativa ${ }^{1}$ entre "informação documentária", "informação semântica" e "informação estética". Cada uma dessas categorias remetem, respectivamente, a contextos informacionais específicos. "Informação documentária" remete a um contexto que "reproduz algo observável, é uma sentença empírica, uma sentença-registro" (CAMPOS, 2004, p. 32); por exemplo: "O livro está sobre a mesa". A "informação semântica” vai além da informação documentária ao acrescentar algo que não é passível de ser observado; acrescenta um "elemento novo" que pode ser, por exemplo, uma categoria de "verdadeiro" ou "falso": "O livro está sobre a mesa é uma sentença verdadeira". A "informação estética”, por sua vez, transcende a semântica, agregando elementos de "imprevisibilidade", "surpresa", improbabilidade, na "organização dos signos": "Mesa seca, no osso, sem o viço de origem" (FREITAS FILHO, 2003, p. 58).

Ao definir essas distinções, Bense elabora o conceito de "fragilidade" da informação estética: "Enquanto a informação documentária e também a semântica admitem diversas codificações, podem ser transmitidas de várias maneiras (...), a informação estética não pode ser codificada senão pela forma em que foi transmitida pelo artista" (CAMPOS, 2004, p. 33). Ou seja, a informação estética não pode ser parafraseada. Qualquer mudança em sua estrutura acarretaria uma mudança de informação: ela deixaria de ser estética e passaria a ser outra - semântica ou documentária.

A partir daí é possível depreender que a informação estética diz respeito exclusivamente ao campo artístico e, mais do que isso, por levar em conta a estruturação sígnica, diz respeito exclusivamente à literatura.

Se por um lado a concepção artística em Fabri enfatiza a tautologia - a arte refere-se a si mesma -, Bense enfatiza a organização dos signos componentes da mensagem, que se estruturam de

\footnotetext{
${ }^{1}$ A esse respeito ver: BENSE, Max. Nova estética. E sua apreciação crítica por Haroldo de Campos: “A Nova Estética de Max Bense” In: CAMPOS, Haroldo de. Metalinguagem e outras metas. São Paulo: Perspectiva, 2004.
} 
maneira inesperada e original. O que ambas as concepções têm em comum é uma apreensão formal do objeto artístico.

Ao levar essa discussão para o campo da tradução, novamente um problema é gerado: como traduzir uma informação cuja mudança em sua estrutura acarreta uma perda em sua essência? Diante de uma informação estética, a tradução, entendida em sua acepção genérica e tradicional, é impossível. Faz-se necessária, portanto, outra concepção de tradução - a transcriação. Dentro desse contexto, por meio da transcriação propõe-se recriar na língua de chegada, se não os efeitos iguais, ao menos efeitos similares ou análogos aos que se encontra na língua de partida. A transcriação é, além de crítica, também criativa.

Por fim, Haroldo de Campos articula o que considera seu exemplo máximo no que se refere à "tradução criativa": o também poeta Ezra Pound.

Em nosso tempo, o exemplo máximo de tradutor-recriador é, sem dúvida, Ezra Pound. O caminho poético de Pound, a culminar na obra inconclusa Cantares, ainda em progresso, foi sempre pontilhado de aventuras de tradução, através das quais o poeta criticava o seu próprio instrumento linguístico, submetendo-os às mais variadas dicções, e estocava material para seus poemas em preparo. Pound desenvolveu, assim, toda uma teoria da tradução e toda uma reivindicação pela categoria estética da tradução como criação. (CAMPOS, 2004, p. 35)

Segundo o relato de Haroldo de Campos, Pound elaborava suas traduções em vista da composição poética, isto é, o processo tradutório estava intimamente ligado à criação: para produzir novos efeitos em sua poesia, Pound procurava-os noutras poesias, em diferentes línguas.

Sendo assim, a transcriação flerta com a teoria da literatura, já que serve como "crítica de seu instrumento de trabalho", que é a língua. Procura-se produzir efeitos poéticos originais buscando 
em outra língua efeitos particulares e idiossincráticos. Esse é o matiz criativo do conceito transcriação, que já não tem em vista a reprodução de um poema, mas visa traduzir os efeitos da língua de partida na língua de chegada.

[...] para nós, tradução de textos criativos será sempre recriação, ou criação paralela, autônoma porém recíproca. Quanto mais inçado de dificuldades esse texto, mais recriável, mais sedutor enquanto possibilidade aberta de recriação. Numa tradução dessa natureza, não se traduz apenas o significado, traduz-se o próprio signo, ou seja, sua fisicalidade, sua materialidade mesma (propriedades sonoras, de imagética visual, enfim, tudo aquilo que forma, segundo Charles Morris, a iconicidade do signo estético, entendido por signo icônico aquele "que é de certa maneira similar àquilo que ele denota"). O significado, o parâmetro semântico, será apenas e tão-somente a baliza demarcatória do lugar da empresa recriadora. Está-se pois no avesso da chamada tradução literal. (CAMPOS, 2004, p. 35).

Como é possível perceber a partir do fragmento acima, a transcriação trabalha com algumas concepções linguísticas específicas, sendo a mais importante delas a de signo icônico. Esta é um conceito oriundo da Semiótica de Charles Sanders Peirce (2011), que dentre outros tipos de signos, caracterizou o signo icônico como sendo aquele que mantêm entre a instância do signo (imagem acústica, em outra terminologia) e do objeto (aquilo a que o signo se refere) uma relação de analogia: o signo tende a ser o objeto. Um exemplo seria o que o poeta Paulo Leminski utiliza para ilustrar a iconicidade no movimento simbolista: "na grafia fantasista da palavra 'lírio', grafada pelos simbolistas como 'lyrio'” (1990, p. 52). A palavra grafada como "lyrio" constitui-se como ícone pela semelhança entre a forma da letra "y" e a da flor. É um aspecto a ser levado em conta no processo de transcriação, buscando-se soluções criativas para realizar um efeito análogo na língua de chegada. 
A transcriação, portanto, prioriza o efeito estético, que em muitos casos pode estar na própria superfície formal de um texto, sendo que o significado é o resultado dessa articulação de formas; já a tradução literal estabelece em primeiro plano a significação do texto, busca reproduzir na língua de chegada os mesmos efeitos de sentidos obtidos na língua de partida, sendo que o aspecto formal, muitas vezes, é deixado em segundo plano.

É importante esclarecer que o principal intuito deste tópico não é esgotar conceitualmente uma definição para o termo transcriação. Seria uma tarefa inviável, pois o próprio Haroldo de Campos por vezes rearticulou sua concepção tradutória, ora aproximando-a de um contexto estruturalista, como é o caso da discussão deste artigo, ora aproximando de concepções como a de Walter Benjamin, por exemplo. Nosso principal intuito, portanto, é estabelecer um matiz conceitual que se aplique a uma discussão frutífera sobre a transcriação, que será aplicado em uma análise do poema "Blanco”, de Octavio Paz, discutida no próximo tópico.

\section{Transcriação, blanco, transblanco.}

O título deste tópico baseia-se na maneira como Haroldo de Campos se refere ao resultado de sua transcriação do poema "Blanco", de Octavio Paz: "uma operação que chamei 'Transblanco"” (CAMPOS, 1994, p. 09).

Octavio Paz (1914 - 1998) foi um diplomata e escritor mexicano, largamente reconhecido pelos seus ensaios sobre poesia e literatura. Estreou em 1933 com um livro de poemas: Luna silvestre; porém sua obra de maior projeção é o ensaio El arco y la lira, publicado em 1956, cujo principal propósito é uma reflexão sobre a escrita poética e os fatores envolvidos. O livro se desenvolve com reflexões sobre ritmo, linguagem, poesia, criatividade, entre outras categorias relacionadas à prática de poesia, num leque amplo de erudição e referências. 
Um dos divulgadores do nome de Octavio Paz no âmbito cultural brasileiro é Haroldo de Campos, cujo interesse não se limita aos ensaios, mas também se dedica a sua obra poética. Isso se dá pelo caráter experimental e metalinguístico da produção poética de Paz e, nesse sentido, "Blanco" ocupa um lugar central. Nos termos de Haroldo de Campos, é uma experiência de limites. Vejase: Haroldo de Campos, ao propor uma transcriação dos poemas de Octavio Paz, assume um posicionamento similar ao de Ezra Pound, conforme apresentado. Vislumbra no processo tradutório a possibilidade de uma crítica cuja relevância, nesse caso, são os processos inventivos; explorar a materialidade linguística e compor uma poesia, como já dito, de limites.

O poema "Blanco" teve sua primeira edição em 1967, com uma tiragem limitada de menos de 600 exemplares. Dispunha de uma encadernação diferenciada: não se tratava de um livro tradicional, costurado ou em brochura, mas, como relata Haroldo de Campos:

o poema vinha acondicionado numa caixa retangular e era apresentado como um dépliant encadernado entre duas capas (a primeira capa, negra, com um quadrado amarelo nela inscrito; a última, branca, igualmente ornada com um quadrado amarelo; a mesma estrutura em mandala se repetia nas faces exteriores da caixa). Para a leitura, o texto se deixava despregar na vertical, como uma única e longa página "sanfonada". Na composição tipográfica, eram utilizados tipos Bodoni de 36, 18, 14, 12 e 10 pontos, redondos ou em grifo, conforme o caso, e, em determinados segmentos, a cor vermelha. (CAMPOS, 1994, p. 31).

Esse aspecto apresenta-se, de imediato, como um primeiro desafio ao tradutor: apesar de parecer fora do escopo do seu trabalho, o cuidado em respeitar a estruturação do livro-objeto em sua originalidade é fator que deve ser levado em conta, pois um livro que rompe com os padrões tradicionais de apresentação pode gerar efeitos de sentido específicos, e, portanto, influencia em sua lei- 
tura. Para resolver esse aspecto, o poema traduzido foi transposto horizontalmente ao longo das páginas, e deve ser lido como se estivesse segurando um pequeno álbum de fotos; dessa maneira, constitui-se aproximativamente o efeito sanfonado que a leitura original propunha.

Não é intuito deste artigo esgotar toda a transcriação do poema, mas aprofundar em alguns pontos específicos cuja discussão se torna mais interessante devido às soluções encontradas pelo tradutor. Nesse sentido, utilizar-se-á do seguinte recurso: serão colocadas lado a lado as duas versões: ao lado esquerdo, o poema na língua de partida, do lado direito, na língua de chegada. Em seguida, uma discussão sobre as soluções.

Como ponto de início, veja-se o começo do poema:

Quadro 1: O início do poema

\begin{tabular}{|l|l|}
\hline Língua de partida & Língua de chegada \\
\hline el comienzo & o começo \\
el cimiento & o cimento \\
la simiente & a semente \\
latente & latente \\
la palabra en la punta de la lengua & a palavra na ponta da língua \\
inaudita inaudible & inaudita inaudível \\
impar & ímpar \\
grávida nula & grávida nula \\
sin edad & sem idade \\
la enterrada con los ojos abiertos & a enterrada de olhos abertos \\
inocente promiscua & inocente promíscua \\
la palabra & a palavra \\
sin nombre sin habla & sem nome sem fala \\
\hline
\end{tabular}

Fonte: CAMPOS, 1994, sem página 
É característica do poema essa aparente "soltura" das palavras que, por sua vez, estão distribuídas pelo branco da página compondo vários possíveis efeitos de sentido. Em oposição às palavras escritas, o "branco", em remissão ao título do poema, assume a característica de silêncio, sendo que as diferentes maneiras como as palavras se distribuem é uma analogia das diferentes maneiras como elas também podem se manifestar. Por uma questão de conveniência, os versos foram transcritos linearmente.

Viu-se que ao desenrolar do poema assume-se como temática central a tautologia: o poema centrado em si mesmo. Se o poema não faz referências externas, seu início, portanto, é ex abrupto: no primeiro verso tem-se: "el comienzo" - início, começo, simplesmente. As palavras, a partir daí, originam-se uma da outra paronomasticamente, ou seja, seguindo uma semelhança fônica: "as palavras (por força da paronomásia) parecem sair de si mesmas, multiplicarem-se a partir de sua articulação fônica. O sentido é, então uma propriedade do som" (ORTEGA, 1994, p. 149). Isso acontece principalmente nos quatro primeiros versos: "el comeinzo / el cimiento / la simiente / latente". É como uma nova realidade que brota de si mesma, metamorfoseando-se.

No processo de transcriação, tais aspectos tornam-se de fundamental importância, sendo que o tradutor deve escolher na língua de chegada termos que dão conta desse processo, mais do que simplesmente enfatizar os aspectos semânticos. Veja-se no primeiro verso: "el comienzo" - ao invés de traduzir como "o início" ou "a origem", termos cuja sutileza semântica seria mais eficiente -, traduziu-se por "o começo", para que se mantivesse a similaridade entre ambas as línguas.

Nos dois versos seguintes "el cimiento / la simiente", levandose em conta o aspecto estritamente fônico, quase obtém-se a mesma palavra, a não ser pelas sutilizas paralelísticas entre os fonemas destacados em caixa-alta: "El cimientO" e "IA simientE". Note que o eu-lírico opta pelo termo menos comum "simiente" em lugar de "semillas", para consolidar o efeito paronomástico, e ainda por cima gerar uma sutileza semântica: "cimiento", também denota 
"raiz" ou "princípio", ou seja, abrange o campo semântico de "semillas", corroborando a leitura de que as palavras originam-se das próprias palavras. Todos esses aspectos mantêm-se na tradução: “o cimento / a semente"; tanto o paralelismo fônico quanto a sutileza semântica são mantidos, já que em português "cimento" também pode se referir a um elemento de "fundação", ou seja, que ocupa um lugar originário.

Entre os versos seis e nove há um paralelismo fônico entre os fonemas /i/ e /a/, conforme destacado:
6. InAudItA InAudIble
7. ImpAr
8. grAvIdA nula
9. sIn edAd

Observe que o paralelismo se dá entre uma vogal aberta /a/ e uma fechada /i/, compondo um espectro de variação entre abertas e fechadas. Esse espectro, por sua vez, gera um efeito de sentido: é como se houvesse, no poema, um movimento de palpitação; ou melhor: é como se o próprio poema palpitasse. O momento é propício, pois trata-se da gênese do poema: seu nascimento coincide com suas primeiras "palpitações".

Esse aspecto leva a utilização da palavra incomum no idioma espanhol "grávida", ao invés de "embarazada". Isso porque em "grávida" o paralelismo entre /a/ e /i/ se mantém - grAvIdA - o que não aconteceria no segundo. Ou seja, esse movimento revela a linguagem manifestando sua própria vida que se inicia, gerando a si mesma e, por sua vez, enquadra-se na concepção tautológica apresentada acima.

Todos esses efeitos de sentido devem ser levados em conta no processo de transcriação. Se a língua de chegada não permite recriar um efeito igual, impõe-se a tarefa de recriar um efeito similar ou análogo. No caso da língua portuguesa, as palavras mantiveram-se quase as mesmas, a não ser pequenas mudanças como no 
verso nove, em que o termo "sin" é traduzido por "sem", que apesar disso, mantém semelhança fônica.

Nessa primeira demonstração de como se dá o processo transcriativo, é possível perceber como se articula a tautologia na arte. A semântica decorre do aspecto organizacional da forma, de como os fonemas estão distribuídos e de como as palavras estão articuladas. Por isso é conveniente um posicionamento criativo, de emular na língua de chegada esses aspectos cuja dimensão semântica não deixa perceber. Diz-se que o significante ganha autonomia.

Vejamos um segundo excerto:

Quadro 2: A consolidação do poema

\begin{tabular}{|l|l|}
\hline Língua de partida & Língua de chegada \\
\hline En el centro & No centro \\
Del mundo del cuerpo del espíritu & Do mundo do corpo do espírito \\
La grieta El resplandor & A brecha O resplendor \\
No & Não \\
En el remolino de las & No remoinho das desaparições \\
desapariciones & \\
El torbellino de las apariciones & O torvelinho das aparições \\
Sí & Sim \\
El árbol de los nombres & A árvore dos nomes \\
No & Não \\
Es una palabra & É uma palavra \\
Sí & Sim \\
Es una palabra & É uma palavra \\
Aire son nada & Ar som nada \\
Son & São \\
Este insecto & Este inseto \\
Revoloteando entre las líneas & Volitando por entre as linhas \\
De la página & Da página \\
Inacabada & Inacabada \\
Inacabable & Inacabável \\
\hline
\end{tabular}




\begin{tabular}{|l|l|}
\hline El pensamiento & O pensamento \\
Revoloteando & Volitando \\
Entre estas palabras & Entre estas palavras \\
Son & São/Som \\
Tus pasos en el cuarto vecino & Teus passos no quarto vizinho \\
Los pájaros que regresan & Os pássaros que regressam \\
El árbol nim que nos protege & A árvore nim que nos protege \\
Los protege & Os protege \\
Sus ramas acallan al trueno & Seus ramos abafam o trovão \\
Apagan al relámpago & Apagam o relâmpago \\
En su follaje bebe agua la sequía & A seca bebe água em sua \\
Son & folhagem \\
Esta noche & Som/São \\
(Esta música) & Esta noite \\
& (Esta música) \\
\hline
\end{tabular}

Fonte: CAMPOS, 1994, sem página

Do excerto anterior foi possível demonstrar uma autonomia da forma sobre o conteúdo. Do paralelismo entre as vogais /a/ e /i/, constituía-se um efeito de pulsação devido à oposição entre o movimento aberto/fechado das vogais. Conforme o poema avança, o que se manifesta no plano formal começa a se manifestar no campo semântico e este, a constituir-se.

A oscilação entre as ideias começa a se fazer mais evidente e pode ser identificada de maneira mais clara entre os seguintes versos:

4. No

5. En el remolino de las desapariciones

6. El torbellino de las apariciones

7. Sí

8. El árbol de los nombres

9. No

10. Es una palabra

11. Sí 
Observe-se a oscilação entre os versos 4, 7, 9 e 11: “No / Sí / No / Sï", respectivamente. Da mesma forma que no excerto anterior a oscilação se dava entre fonemas, agora se dá numa antítese entre os termos "No" e "Sî́" e, portanto, o campo semântico começa a se formar. Nos versos 5 e 6 "En el remolino de las desapariciones / El torbellino de las apariciones” também há uma antítese entre "desapariciones" e "apariciones"; porém a sinonímia entre "remolino" e "torbellino" parece contradizer essa perspectiva. Essa contradição, porém, é aparente: apesar da atitude mais esperada ser o uso de uma antítese, não uma sinonímia, os dois termos designam um movimento circular - "remollino" e "torvellino" designam um movimento circular ocasionado pelo encontro de águas.

Vejamos com mais detalhes: o movimento circular é ocasionado pelo encontro de águas que segue cursos opostos. Nesse sentido, o poema simboliza a união de termos opostos. Isso se dá desde os elementos mais básicos: os fonemas, até os elementos mais complexos: os sentidos. Porém a oposição entre os elementos não se dá de maneira isolada, ela só se constitui e ganha sentido a partir do momento em que um se impõe em frente do outro. A união desses opostos, portanto, gera um ritmo binário que é constituinte de todo o poema: desde a oposição fônica entre /a/ e /i/, perpassando pelas antíteses "No"/"Sí" e continuando nos paradoxos "En el remolino de las desapariciones / El tobellino de las apariciones", ou como no verso 30: "En su follaje bebe agua la sequía", até se manifestar de maneira plena no verso 33: "(Esta música)", ou seja, sabe-se que a música constitui-se pelo ritmo da vibração - movimento de ir e vir - de cordas ou do toque em um tambor, por exemplo.

Eis outro aspecto que deve ser levado em conta no processo de transcriação: não apenas os efeitos de sentido agora apresentados, mas também seu encadeamento íntimo em relação aos efeitos constituídos anteriormente, respeitando o ritmo binário que, mais do que um efeito de sentido, é um elemento constituinte do poema. Apesar de Haroldo de Campos não explicitar essa leitura em seus comentários, reproduz na língua de chegada os efeitos aqui identificados. "En el remolino de las desapariciones / El torbellino 
de las apariciones" traduz como: "No remoinho das desaparições / O torvelinho das aparições"; "remoinho" e "torvelinho" possuem a mesma designação dos seus termos respectivos na língua de partida, assim como mantém a relação de sinonímia.

O excerto foi escolhido também por uma característica típica do processo de transcriação, que é acrescentar na língua de chegada termos que originalmente não se encontram na língua de partida, mas dão conta de constituir os mesmos efeitos de sentido. Veja-se os versos 13, 14, 23 e 31:

\section{Aire son nada \\ 14. Son \\ (...) \\ 23. Son \\ (...) \\ 31. Son}

(ênfase minha)

"Son" perpassa ao longo dos versos constituindo um efeito de eco que, por sua vez, se caracteriza por ser uma alternância repetida entre som e silêncio: novamente o ritmo binário. Comumente "son" é utilizado como verbo "ser" na terceira pessoa do plural no presente do indicativo: "são". Haroldo de Campos, por sua vez, identifica uma sutileza: a possibilidade de se compreender "son" na acepção de "som que afeta de maneira agradável aos ouvidos, especialmente aqueles produzidos com arte" 2 . Tem-se um caso de homofonia, algo irreproduzível na língua de chegada: de imediato haveria de optar entre a colocação de "são" (verbo) ou "som" (substantivo). Como solução, Haroldo de Campos traduz da seguinte maneira:

${ }^{2}$ Conforme a página virtual do dicionário da Real Academia Española, disponível em: http://lema.rae.es/drae/?val=son 


\title{
13. Ar som nada \\ 14. São \\ (...) \\ 23. São/Som \\ (...) \\ 31. Som/São
}

Ou seja, o tradutor acrescenta na língua de chegada os dois termos, de modo que abranjam o efeito discutido anteriormente.

\begin{abstract}
No poema de Paz, SON funciona como SÃO (verbo "ser") e como substantivo, SOM, matiz que escapa, muitas vezes, aos próprios leitores de fala espanhola, quando não atentam às conotações sintáticas do contexto em que esse lexema opera. (...) De minha parte, desdobro em quase-eco o jogo ambíguo e utilizo, inclusive, o espaço gráfico (...), para reconfigurar fonossemanticamente essa dúplice nuança, tão relevante para o desfecho do poema "reflexivo" (SÃO) e "sensorial" (SOM) de Octavio Paz (CAMPOS, 1994, p. 191).
\end{abstract}

A ambiguidade é parte constituinte do poema; desse modo, ao optar entre um termo ou outro, lesionar-se-ia a abrangência semântica do mesmo. Veja como o processo de transcriação pode abranger todos os aspectos textuais: utiliza-se do espaço gráfico para transpor na língua de chegada as nuances fônicas e semânticas presentes na língua de partida.

\section{Conclusão}

A partir do levantamento anterior é possível dizer que transcriação se refere a um processo que se subdivide em três aspectos: trata-se de uma crítica, de uma criação e de uma tradução.

O intuito deste artigo não é esgotar conceitualmente o termo, mas apresentar uma dentre várias possibilidades de compreensão. 
Para isso, estabeleceu-se um recorte teórico dentro da obra de Haroldo de Campos, um dos principais articuladores desse "conceito", que fosse coerente à proposta de tradução, feita por ele mesmo, do poema "Blanco", de Octavio Paz.

A meta central da transcriação é recriar na língua de chegada efeitos, se não iguais, análogos aos que se constituem na língua de partida. Mas diferentemente de um processo "tradicional" de tradução, em que a reconstituição semântica é fator primordial, nem sempre o mesmo se aplica a transcriação. Principalmente a partir do século XX e, mais especificamente, de sua segunda metade, alguns movimentos artísticos de vanguarda - como é o caso do Concretismo no Brasil - priorizam a instância formal. Essa visão também é assumida em movimentos teóricos, como o Estruturalismo de Roman Jakobson e Tzvetan Todorov, por exemplo. Os textos poéticos passaram a ser articulados em vista de sua organização formal, seja pela sonoridade, pela grafia, pelos recursos que a materialidade do significante permite. Isso significa que transcriação é um processo criativo de tradução, e pode se adaptar de acordo com a concepção artística em voga. Dentro das propostas de Haroldo de Campos, a arte constitui-se por ser tautológica, ou seja, atuo-referencial.

Além disso, seu interesse reside na arte de invenção e, assim, sua concepção de tradução também é de invenção: o principal intuito é recriar na língua de chegada efeitos de sentido, se não iguais, pelo menos similares ou análogos aos que se constituem na língua de partida. Para conseguir atingir essa meta, vale explorar todos os aspectos que envolvem um texto: desde seu aspecto fônico, ao semântico e gráfico.

É o que Haroldo de Campos pratica na transcriação de "Blanco", cuja sonoridade é preponderante num primeiro momento. A partir dela constitui-se o aspecto semântico do poema e seu fator fundante: o ritmo binário. 


\section{Referências}

CAMPOS, Haroldo de; PAZ, Octavio. Transblanco. São Paulo: Siciliano, 1994.

CAMPOS, Haroldo de. Da Tradução como Criação e como Crítica. In: Metalinguagem e outras metas. São Paulo: Perspectiva, 2004.

FREITAS FILHO, Armando. Máquina de escrever: poesia reunida e revista. Rio de Janeiro: Nova Fronteira, 2003.

JAKOBSON, Roman. Linguística e comunicação. Tradução de Izidoro Blikstein, José Paulo Paes. São Paulo: Cultrix, 1971.

LEMINSKI, Paulo. Vida. São Paulo: Editoria Sulinas, 1990.

ORTEGA, Julio. Uma Hipótese de Leitura. Tradução de Haroldo de Campos. In: CAMPOS, Haroldo de; PAZ, Octavio. Transblanco: São Paulo: Siciliano, 1994.

PEIRCE, Charles Sanders. Semiótica. Tradução de Teixeira Coelho. São Paulo: Perspectiva, 2011.

Recebido em: 01/11/2015

Aceito em: 26/02/2016

Publicado em maio de 2016 